\title{
Reticular chemistry at the atomic, molecular, and framework scales
}

\author{
Yue-Biao Zhang ${ }^{1}(\bowtie)$, Qiaowei Li ${ }^{2}(\bowtie)$, and Hexiang Deng ${ }^{3}(\bowtie)$ \\ ${ }^{1}$ School of Physical Science and Technology, ShanghaiTech University, Shanghai 201210, China \\ ${ }^{2}$ Department of Chemistry, Collaborative Innovation Center of Chemistry for Energy Materials (iChEM) and Shanghai Key Laboratory of \\ Molecular Catalysis and Innovative Materials, Fudan University, Shanghai 200438, China \\ ${ }^{3}$ Key Laboratory of Biomedical Polymers, Ministry of Education, College of Chemistry and Molecular Sciences, The Institute of Technological \\ Sciences and The Institute for Advanced Studies, Wuhan University, Wuhan 430072, China
}

(c) Tsinghua University Press and Springer-Verlag GmbH Germany, part of Springer Nature 2020

\begin{abstract}
“There's plenty of room at the bottom." Feynman's talk has been frequently quoted for the advent of nanoscience, which gives profound perspectives of arranging atoms in the way we want [1]. With the same bottom-up manner, reticular chemistry is concerned with linking of molecular building blocks by strong bonds to make crystalline open frameworks [2]. The most important category practicing this bottom-up strategy at framework scale is metal-organic frameworks (MOFs) coined in 1995 [3], which leads to synthetic crystals featuring ultrahigh surface areas, fine-tuned pore metrics, and multivariate functionalities [4-16]. The same strategy has also been successfully extended to crystalline covalent organic frameworks (COFs) from entirely organic building blocks through strong covalent bonds [17-19], whose crystal structures are now possible to be determined by $3 \mathrm{D}$ electron diffraction [20] and even X-ray diffraction [21]. Recently, molecular weaving adds exotic flavors to reticular chemistry enabling the interlacing, knitting, and crocheting with molecular threads to make resilient nanotextiles [22]. We envision the future of this field lays on the anisotropic reticular chemistry [23], where the components can be precisely arranged and manipulated along a specific direction. The atomic arrangement of various metals in the structures can be eventually read, written, and edited [24]. Reticular chemistry has definitely opened up a new way to align molecular machines, or nano circuits in apportioned space. Thus, multiple operations in series or in parallel can be achieved at the framework scale.
\end{abstract}

The 2019 Nano Research Award was presented to Prof. Xinhe Bao and Prof. Omar M. Yaghi. We take this great opportunity to showcase the prosperity and diversity in the reticular chemistry community in a form of this special issue. The central theme of the issue is "Future Directions of Reticular Chemistry" with emphasis on precision in all dimensions (0D, 1D, 2D, and 3D) and at atomic, molecular, and framework scales.

The core of reticular chemistry is practicing the geometric principles to yield new structures and developing the framework chemistry. Mirica and co-worker report the design of a new $\mathrm{d}-\pi$ conjugated $2 \mathrm{D}$ MOF with large pore aperture, tunable electrical conductivity, and temperature dependent band gaps (Front Cover Artwork) [25]. Farha, Chen, and co-workers report the reticular design of a new series of isoreticular MOFs composed of a trigonal planar uranyl building block and hexagonal-prismatic linkers with various arm lengths [26].
Zhao, Jiang, Qian, and co-workers report the reticular synthesis of $2 \mathrm{D}$ honeycomb-like COFs by altering connecting sequences of low-symmetric triangular building blocks [27]. Xiang, Zhang, Liu, and co-workers report the construction of metal-organic nanotubes based on metallomacrocycles with enhanced proton conductivity decorated with dangling carboxylic acid groups in the channels [28]. Choe, Lim, and co-workers report the reticular design of metal-organic polygons based on a trinuclear $\mathrm{Zr}(\mathrm{IV})$ cluster by interplaying of the geometrically frustrated ligand and secondary building unit [29]. Sun, Tian, and coworkers report the improvement of spin-crossover performance by linking the Fe-based mononuclear centers into a metalorganic square frame [30].

Molecular motion amplification, building block transformation, molecular machinery, and electronic communications within the frameworks have emerged in the compartments of MOFs with molecular precision. Queen and co-workers unveil the structural motions in a MOF responsible for the large anisotropic negative thermal expansion by in-situ X-ray diffraction and diffuse reflectance infrared Fourier transform spectroscopy [31]. Moon, Lee, and co-workers report the structural transformation of MOFs by controlling the secondary building unit (SBU) geometries via the addition of either basic or acidic moieties [32]. Loeb and co-workers report the installation of rigid T-shaped linkers and their [2] rotaxane analogs in MOF for probing the motion of the 24-memebered macrocycle threaded onto the rigid backbone by variable-temperature solid-state NMR spectroscopy [33]. Shustova and co-workers overview the progress of harnessing the versatile MOF platform to accentuate the photophysical properties of integrated chromophores for advancing nanoscale photonics and portable electronics [34].

Traditional nanoscience also brings in new thinking in understanding and manipulating the compositions and interactions at the interfaces between heterojunctions of MOFs. Wöll and co-worker review the synthetic strategies and applications of hierarchical MOF-on-MOF epitaxial heterostructures [35]. Hmadeh, Al-Ghoul, and workers report the reaction diffusion framework for preparing multivariate MOF-199 structures for dye removal from water [36]. Furukawa and co-workers report the post-synthetic pillaring a 2D layer MOF to form picture-frame crystals for tuning their flexibility to have rigid, elastic, and shape memory modes [37]. Xu, Yao, and co-workers report a dual-ligand strategy to modulate 
the chemiresistive sensitivity and selectivity of electronically conductive MOF thin films prepared by spray layer-by-layer assembly method [38]. Zhang, Li, Jiang, and co-workers report a directly stirring method for preparing porphyrinic metalorganic framework, enabling the encapsulation of metal nanoparticles at room temperature [39].

Catalytic sites with atomic distribution and fine-tuned nano-confinement space are manifested in the heterogeneous catalysis. Designing multiple active sites bring with the whole performance exceeding the sum of the parts. Horcajada, García, and co-workers report a robust microporous $2 \mathrm{D} \mathrm{Ni}$-phosphonate MOF featuring stable photocatalytic activity in hydrogen evolution and overall water splitting [40]. Maspoch, Alemán, Mas-Ballesté, Imaz, and co-workers designed a series of MOFs with squaramide organocatalysts for investigating their nanoconfinement effect and catalytic profiles in Friedel-Crafts alkylation and epoxide ring-opening catalytic reactions [41]. Liu and co-workers report the rational tuning of asymmetrically catalytic enantioselectivity of a series of isoreticular MOFs by changing the electronegativities of metal centers and modifying the steric hindrance of linker [42]. Wang and coworkers report a two-dimensional layer of Pd-functionalized MOF for heterogeneous catalyst and a reusable solid reagent to fluorinate a broad scope of aromatic compounds [43]. Li, Ordomsky, Yang, and co-workers report the nanocomposited $\mathrm{Ru} @ \mathrm{MOF}$ tandem catalyst for direct alcohol to acetal conversion of monoalcohols and diols without formation of carboxylic acids [44]. Shin, Choi, and co-workers report the anchoring of single Pd atoms on discrete metal-organic polyhedra for Suzuki-Miyaura cross-coupling reaction with various substrates in aqueous media [45]. Gándara, de la Peña-O’Shea, Monge, Álvarez-Gálvan, and co-workers exploited the precision of an atomically sequenced MOF to derive supported metal nanoparticles as an efficient catalyst for the reduction of carbon dioxide in the reverse water-gas shift reaction [46]. Zang and co-workers report the oxygen vacancy engineering of calcium cobaltate for electrocatalytic nitrogen reduction reaction [47].

By virtue of the precise pore metrics, sophisticated pore chemistry, reticular structures are ideal materials for gas storage and adsorptive separation. Chen, Xiang, and co-workers report the design of microporous Al-MOF for high $\mathrm{CH}_{4}, \mathrm{H}_{2}$, and $\mathrm{CO}_{2}$ storage [48]. Ma, Kumar, and co-workers report a robust soc-MOF for on-board methane storage featuring high gravimetric uptake and volumetric deliverable capacity [49]. Yuan, $\mathrm{He}$, and co-workers report the efficient separation of hydrogen isotopes through a new 3D Cu-MOF adopting the chabazite net [50]. Liu, Han, and co-workers report the reticular design of triangular channels of a MOF for efficient separation of hexane isomers [51]. Galli, Navarro, and co-workers report the positive impact of functionalization in a series of $\mathrm{Zn}-\mathrm{MOF}$ with 1D square channels for hexane isomers separation [52]. Xing, Cui, and co-workers report an anion-pillared MOF for separation of C5 olefins of trans-2-pentene, 1-pentene and isoprene [53]. Duan, Y. Wang, Z. Wang, and co-worker reports the post-synthetic metalation of MOFs for enhanced $\mathrm{C}_{2} \mathrm{H}_{2} / \mathrm{CO}_{2}$ separation (Back Cover Artwork) [54].

Overall, the "Future Directions of Reticular Chemistry" special issue contains 2 Review Articles and 28 Research Articles having contributions from 17 countries and regions. We would like to thank the authors for their high-quality contributions, the reviewers for elevating the manuscripts, and the editorial team for their tremendous support. Congratulations to Prof. Omar M. Yaghi on jointly winning the 2019 Nano Research Award.

\section{References}

[1] Feynman, R. P. There's plenty of room at the bottom. Eng. Sci. 1960, 23, 22-36.

[2] Yaghi, O. M.; Kalmutzki, M. J.; Diercks, C. S. Introduction to reticular chemistry: Metal-organic frameworks and covalent organic frameworks; Wiley-VCH, Weinheim, 2019; pp 1-509.

[3] Yaghi, O. M.; Li, G.; Li, H. Selective binding and removal of guests in a microporous metal-organic framework. Nature 1995, 378, 703-706.

[4] Li, H.; Eddaoudi, M.; Groy, T. L.; Yaghi, O. M. Stablishing microporosity in open metal-organic frameworks: Gas sorption isotherms for $\mathrm{Zn}(\mathrm{BDC})(\mathrm{BDC}=1,4$-benzenedicarboxylate). J. Am. Chem. Soc. 1998, 120, 8571-8572.

[5] Li, H.; Eddaoudi, M.; O'Keeffe, M.; Yaghi, O. M. Design and synthesis of an exceptionally stable and highly porous metal-organic framework. Nature 1999, 402, 276-279.

[6] Chae, H. K.; Siberio-Perez, D. Y.; Kim, J.; Go, Y.-B.; Eddaoudi, M.; Matzger, A. J.; O'Keeffe, M.; Yaghi, O. M. A route to high surface area, porosity and inclusion of large molecules in crystals. Nature 2004, 427, 523-527.

[7] Furukawa, H.; Ko, N.; Go, Y. B.; Aratani, N.; Choi, S. B.; Choi, E.; Yazaydin, A. O.; Snurr, R. Q.; O'Keeffe, M.; Kim, J. et al. Ultra-high porosity in metal-organic frameworks. Science 2010, 239, 424-428.

[8] Chen, B.; Eddaoudi, M.; Hyde, S. T.; O'Keeffe, M.; Yaghi, O. M. Interwoven metal-organic framework on a periodic minimal surface with extra-large pores. Science 2001, 291, 1021-1023.

[9] Deng, H.; Grunder, S; Cordova, K. E.; Valente, C.; Furukawa, H.; Hmadeh, M.; Gándara, F.; Whalley, A. C.; Liu, Z.; Asahina, S. et al. Large-pore apertures in a series of metal-organic frameworks. Science 2012, 336, 1018-1023.

[10] Eddaoudi, M.; Kim, J.; Rosi, N. L.; Vodak, D. T.; Wachter, J.; O'Keeffe, M.; Yaghi, O. M. Systematic design of pore size and functionality in isoreticular metal-organic frameworks and application in methane storage. Science 2002, 295, 469-472.

[11] Deng, H.; Doonan, C. J.; Furukawa, H.; Ferreira, R. B.; Towne, J.; Knobler, C. B.; Wang, B.; Yaghi, O. M. Multiple functional groups of varying ratios in metal-organic frameworks. Science 2010, 327, 846-850.

[12] Li, Q.; Zhang, W.; Miljanić, O. Š.; Sue, C.-H.; Zhao, Y.-L.; Liu, L.; Knobler, C. B.; Stoddart, J. F.; Yaghi, O. M. Docking in metal-organic frameworks. Science 2009, 325, 855-859.

[13] Lee, S.; Kapustin, E.; Yaghi, O. M. Coordinative alignment of molecules in chiral metal-organic frameworks. Science 2016, 353, 808-811.

[14] Phan, A.; Doonan, C. J.; Uribe-Romo, F. J.; Knobler, C. B.; O'Keeffe, M.; Yaghi, O. M. Synthesis, structure, and carbon dioxide capture properties of zeolitic imidazolate frameworks. Acc. Chem. Res. 2010, 43, 58-67.

[15] Wang, B.; Côté, A. P.; Furukawa, H.; O'Keeffe, M.; Yaghi, O. M. Colossal cages in zeolitic imidazolate frameworks as selective carbon dioxide reservoirs. Nature 2008, 453, 207-211.

[16] Yang, J.; Zhang, Y.; Liu, Q.; Trickett, C. A.; Gutierrez-Puebla, E.; Monge, M. Á.; Cong, H.; Aldossary, A.; Deng, H.; Yaghi, O. M. Principles of designing extra-large pore openings and cages in zeolitic imidazolate frameworks. J. Am. Chem. Soc. 2017, 139, 6448-6455.

[17] Côté, A. P.; Benin, A. I.; Ockwig, N. W.; Matzger, A. J.; O'Keeffe, M.; Yaghi, O. M. Porous, crystalline, covalent organic frameworks. Science 2005, 310, 1166-1170.

[18] El-Kaderi, H. M.; Hunt, J. R.; Mendoza-Cortés, J. L.; Côté, A. P.; Taylor, R. E.; O'Keeffe, M.; Yaghi, O. M.; Designed synthesis of 3D covalent organic frameworks. Science 2007, 316, 268-272.

[19] Gropp, C.; Ma, T.; Hanikel, N.; Yaghi, O. M. Design of higher valency in covalent organic frameworks. Science 2020, 370, eabd6406.

[20] Zhang, Y.-B.; Su, J.; Furukawa, H.; Yun, Y.; Gándara, F.; Duong, A.; Zou, X.; Yaghi, O. M. Single-crystal structure of a covalent organic framework. J. Am. Chem. Soc. 2013, 135, 16336-16339.

[21] Ma, T.; Kapustin, E. A.; Yin, S. X.; Liang, L.; Zhou, Z.; Niu, J.; Li, L.; Wang, Y.; Su, J.; Li, J. et al. Single-crystal X-ray diffraction structures of covalent organic frameworks. Science 2018, 361, 48-52.

[22] Liu, Y.; Ma, Y.; Zhao, Y.; Sun, X.; Gándara, F.; Furukawa, H.; Liu, Z.; Zhu, H.; Zhu, C.; Suenaga, K. et al. Weaving of organic threads into a crystalline covalent organic framework. Science 2016, 351, 365-369. 
[23] Xu, W.; Tu, B.; Shu, Y.; Liang, C.-C.; Diercks, C. S.; Yaghi, O. M.; Zhang, Y.-B.; Deng, H.; Li, Q. Anisotropic reticular chemistry. Nat. Rev. Mater. 2020, 5, 764-779.

[24] Ji, Z.; Li, T.; Yaghi, O. M.; Sequencing of metals in multivariate metal-organic frameworks. Science 2020, 369, 674-680.

[25] Meng, Z.; Mirica, K. A. Two-dimensional $d-\pi$ conjugated metalorganic framework based on hexahydroxytrinaphthylene. Nano Res. 2021, 14, 369-375.

[26] Chen, Z.-J.; Li, P.-H.; Zhang, X.; Mian, M. R.; Wang, X.-J.; Li, P.; Liu, Z.-C.; O'Keeffe, M.; Stoddart, J. F.; Farha, O. K. Reticular exploration of uranium-based metal-organic frameworks with hexacarboxylate building units. Nano Res. 2021, 14, 376-380.

[27] Ma, D.-L.; Qian, C.; Qi, Q.-Y.; Zhong, Z.-R.; Jiang, G.-F.; Zhao, X. Effects of connecting sequences of building blocks on reticular synthesis of covalent organic frameworks. Nano Res. 2021, 14, 381386.

[28] Lin, Q.-J.; Ye, Y.-X.; Liu, L.-Z.; Yao, Z.-Z.; Li, Z.-Y.; Wang, L.-H.; Liu, C.-L.; Zhang, Z.-J.; Xiang, S.-C. High proton conductivity in metalloring-cluster based metalorganic nanotubes. Nano Res. 2021, 14, 387-391.

[29] Kim, J.; Nam, D.; Kitagawa, H.; Lim, D.-W.; Choe, W. Discovery of Zr-based metal-organic polygon: Unveiling new design opportunities in reticular chemistry. Nano Res. 2021, 14, 392-397.

[30] Wang, Z.; Zhou, L.-P.; Cai, L.-X.; Tian, C.-B.; Sun, Q.-F. From a mononuclear $\mathrm{FeL}_{2}$ complex to a $\mathrm{Fe}_{4} \mathrm{~L}_{4}$ molecular square: Designed assembly and spin-crossover property. Nano Res. 2021, 14, 398-403.

[31] Asgari, M.; Kochetygov, I.; Abedini, H.; Queen, W. L. Large anisotropic negative thermal expansion in $\mathrm{Cu}$-TDPAT metalorganic framework: A combined in situ X-ray diffraction and DRIFTS study. Nano Res. 2021, 14, 404-410.

[32] Kim, J.; Ha, J.; Lee, J. H.; Moon, H. R. Solid-state phase transformations toward a metal-organic framework of 7-connected $\mathrm{Zn}_{4} \mathrm{O}$ secondary building units. Nano Res. 2021, 14, 411-416.

[33] Stirk, A. J.; Wilson, B. H.; O'Keefe, C. A.; Amarne, H.; Zhu, K.; Schurko, R. W.; Loeb, S. J. Applying reticular synthesis to the design of Cu-based MOFs with mechanically interlocked linkers. Nano Res. 2021, 14, 417-422.

[34] Martin, C. R.; Kittikhunnatham, P.; Leith, G. A.; Berseneva, A. A.; Park, K. C.; Greytak, A. B.; Shustova, N. B. Let the light be a guide: Chromophore communication in metalorganic frameworks. Nano Res. 2021, 14, 338-354.

[35] Haldar, R.; Wöll, C. Hierarchical assemblies of molecular frameworks-MOF-on-MOF epitaxial heterostructures. Nano Res. 2021, 14, 355-368.

[36] Issa, R.; Ibrahim, F. A.; Al-Ghoul, M.; Hmadeh, M. Controlled growth and composition of multivariate metal-organic frameworks-199 via a reaction-diffusion process. Nano Res. 2021, 14, 423-431.

[37] Sumida, K.; Horike, N.; Furukawa, S. Dynamic properties of a flexible metal-organic framework exhibiting a unique "picture frame"-like crystal morphology. Nano Res. 2021, 14, 432-437.

[38] Wu, A.-Q.; Wang, W.-Q.; Zhan, H.-B.; Cao, L.-A.; Ye, X.-L.; Zheng, J.-J.; Kumar, P. N.; Chiranjeevulu, K.; Deng, W.-H.; Wang, G.-E. et al. Layer-by-layer assembled dual-ligand conductive MOF nano-film with modulated chemiresistive sensitivity and selectivity. Nano Res. 2021, 14, 438-443.

[39] He, H.-H.; Li, L.-Y.; Liu, Y.; Kassymova, M.; Li, D.-D.; Zhang, L.-L.; Jiang, H.-L. Rapid room-temperature synthesis of a porphyrinic MOF for encapsulating metal nanoparticles. Nano Res. 2021, 14, 444-449.

[40] Abraira, P. S.; Vilela, S. M. F.; Babaryk, A. A.; Antonino, M. C.;
Gregorio, P.; Salles, F.; Navalón, S.; García, H.; Horcajada, P. Nickel phosphonate MOF as efficient water splitting photocatalyst. Nano Res. 2021, 14, 450-457.

[41] Ribas, A. B.; Vignatti, C.; Almarza, A. J.; Barrera, J. L.; Dolatkhah, Z.; Gándara, F.; Imaz, I.; Mas-Ballesté, R.; Alemán, J.; Maspoch, D. Heterogeneous catalysts with programmable topologies generated by reticulation of organocatalysts into metal-organic frameworks: The case of squaramide. Nano Res. 2021, 14, 458-465.

[42] Chen, X.; Qiao, Z.-W.; Hou, B.; Jiang, H.; Gong, W.; Dong, J.-Q.; Li, H.-Y.; Cui, Y.; Liu, Y. Chiral metal-organic frameworks with tunable catalytic selectivity in asymmetric transfer hydrogenation reactions. Nano Res. 2021, 14, 466-472.

[43] Shi, W.-J.; Zeng, L.-Z.; Cao, L.-Y.; Huang, Y.; Wang, C.; Lin, W.-B. Metal-organic layers as reusable solid fluorination reagents and heterogeneous catalysts for aromatic fluorination. Nano Res. 2021, $14,473-478$.

[44] Zhang, S.-W.; Li, J. P. H.; Zhao, J.-P.; Wu, D.; Yuan, B.; Hernández, W. Y.; Zhou, W.-J.; He, T.; Yu, Y.; Yang, Y. et al. Direct aerobic oxidation of monoalcohol and diols to acetals using tandem Ru@MOF catalysts. Nano Res. 2021, 14, 479-485.

[45] Kim, S.; Jee, S.; Choi, K. M.; Shin, D.-S. Single-atom Pd catalyst anchored on Zr-based metal-organic polyhedra for Suzuki-Miyaura cross coupling reactions in aqueous media. Nano Res. 2021, 14, 486-492.

[46] Blas, C. C.; Álvarez-Galván, C.; Orench, I. P.; Sánchez, A. G.; Oropeza, F. E.; Puebla, E. G.; Monge, Á.; de la Peña-O’Shea, V. A.; Gándara, F. Highly efficient multi-metal catalysts for carbon dioxide reduction prepared from atomically sequenced metal organic frameworks. Nano Res. 2021, 14, 493-500.

[47] Chen, X.-Y.; Li, K.; Yang, X.-X.; Lv, J.-Q.; Sun, S.; Li, S.-Q.; Cheng, D.-M.; Li, B.; Li, Y.-G.; Zang, H.-Y. Oxygen vacancy engineering of calcium cobaltate: A nitrogen fixation electrocatalyst at ambient condition in neutral electrolyte. Nano Res. 2021, 14, 501-506.

[48] Wang, B.; Zhang, X.; Huang, H.-L.; Zhang, Z.-J.; Yildirim, T.; Zhou, W.; Xiang, S.-C.; Chen, B.-L. A microporous aluminum-based metalorganic framework for high methane, hydrogen, and carbon dioxide storage. Nano Res. 2021, 14, 507-511.

[49] Verma, G.; Kumar, S.; Vardhan, H.; Ren, J.; Niu, Z.; Pham, T.; Wojtas, L.; Butikofer, S.; Garcia, J. C E.; Chen, Y.-S. et al. A robust soc-MOF platform exhibiting high gravimetric uptake and volumetric deliverable capacity for on-board methane storage. Nano Res. 2021, $14,512-517$.

[50] Si, Y.-N.; He, X.; Jiang, J.; Duan, Z.-M.; Wang, W.-J.; Yuan, D.-Q. Highly effective $\mathrm{H}_{2} / \mathrm{D}_{2}$ separation in a stable $\mathrm{Cu}$-based metalorganic framework. Nano Res. 2021, 14, 518-525.

[51] Wang, D.-M.; Dong, X.-L.; Han, Y.; Liu, Y.-L. Separation of hexane isomers by introducing "triangular-like and quadrilateral-like channels" in a bcu-type metal-organic framework. Nano Res. 2021, 14, 526-531.

[52] Vismara, R.; Nicola, C. D.; Millán, R. G.-S.; Domasevich, K. V.; Pettinari, C.; Navarro, J. A. R.; Galli, S. Efficient hexane isomers separation in isoreticular bipyrazolate metal-organic frameworks: The role of pore functionalization. Nano Res. 2021, 14, 532-540.

[53] Yu, Y.; Yang, L.-F.; Tan, B.; Hu, J.-B.; Wang, Q.-J.; Cui, X.-L.; Xing, H.-B. Remarkable separation of C5 olefins in anion-pillared hybrid porous materials. Nano Res. 2021, 14, 541-545.

[54] Chen, S.; Behera, N.; Yang, C.; Dong, Q.-B.; Zheng, B.-S.; Li, Y.-Y.; Tang, Q.; Wang, Z.-X.; Wang, Y.-Q.; Duan, J.-G. A chemically stable nanoporous coordination polymer with fixed and free $\mathrm{Cu}^{2+}$ ions for boosted $\mathrm{C}_{2} \mathrm{H}_{2} / \mathrm{CO}_{2}$ separation. Nano Res. 2021, 14, 546-553. 